\title{
Ocorrência de bioagentes patogênicos nos eletrodos utilizados na Estimulação Nervosa Elétrica Transcutânea nos serviços de fisioterapia da Baixada Fluminense RJ Occurrence of pathogenic bioagents on electrodes used in Transcutaneous Nerve Stimulation in physical therapy services in Baixada Fluminense RJ
}

José Tadeu Madeira de Oliveira, M.Sc.*, Antônio Neres Norberg, D.Sc.*, Fábio dos Santos Borges, M.Sc.*, Glória Maria Moraes Vianna da Rosa, M.Sc.*, Ingrid Jardim de Azeredo Souza**, Rafael Jardim de Azeredo Souza***, Ailton da Silva Gonçalves****, Betânia Martins Alhan de Oliveira*****, Fabiano Sanches Guerra******

*Docentes da Universidade Iguaçu, **Docente da Universidade Iguaçu, Especialista em Fisioterapia Cinética Funcional, **Docente da Universidade Iguaşu, Especialista em Fisioterapia Cinética Funcional, ****Farmacêutico graduado pela Universidade Iguaçu, ****Farmacêutica graduada pela Universidade Iguaçu, Especialista em Parasitologia, ******Iniciação científica da Universidade Iguaçu

\section{Resumo}

A Estimulação Nervosa Elétrica Transcutânea (TENS) é uma corrente de baixa intensidade, onde o contato entre o eletrodo e a pele são mecanismos indispensáveis da técnica terapêutica. Os eletrodos são constituídos de borracha siliconizada, acoplados à superfície cutânea com o uso de um gel eletricamente condutivo. Esses eletrodos de tamanho e marcas diversificadas, utilizados em pacientes, foram submetidos à fricção longitudinal com o auxílio de um suabe, em um tempo máximo de duas horas e foram semeados em meio de cultura Brewer e Sabouraud. O crescimento obtido foi repicado para meios de cultura Agar-sangue, Agar-hipertônicomanitol e meio seletivo para Pseudomonas e Staphylococcus. As colônias foram identificadas por caracteres culturais e provas bioquímicas de identificação, através de sistema BioMerieux Vitek. O crescimento fúngico foi identificado por caracteres morfológicos, culturais, provas bioquímicas e morfológicas quando necessárias. Os resultados demonstraram 59,5\% de positividade nas amostras avaliadas para a presença de agentes fúngicos e bacterianos. Sugere-se uma necessidade de prevenção da transmissão de bioagentes por contato, e melhoria na qualidade do atendimento em fisioterapia.

Palavras-chave: bioagentes patogênicos, eletrodos.

\begin{abstract}
The transcutaneous Nerve Stimulation (TNS) is a low intensity current where contact between electrode and skin are indispensable mechanisms of therapy. The electrodes are made of silicone rubber coupling to cutaneous surface using a electrically conductive gel. These electrodes of size and mark diversified used in patients, were submitted to longitudinal friction with support of a swab, in maximum time of two hours and were seed in Brewer and Sabouraud medium. The growth obtained was transplanted to Agar-blood media, Agar-hipertonic-manitol and selective medium to Pseudomonas and Staphylococcus. The colonies were identified by characters of culture and biochemical proof of identification through the BioMerieux Vitek system. The fungal growth was identified by morphological characters, cultural, biochemical and morfological proof when necessary. The results showed 59,5\% of positivity in evaluated samples for the presence of fungal and bacterium agents. Its suggested necessity of preventing bioagents transmission by contact and advance in attendance quality in physical therapy.
\end{abstract}

Key-words: Pathogenic bioagents, electrodes.

\section{Introdução}

Durante séculos, a estimulação elétrica vem sendo utilizada para o alívio da dor. $\mathrm{Na}$ Grécia, enguias elétricas foram utilizadas pelos antigos egípcios no tratamento de lesões e dores de cabeça [1]. Em Roma, um escravo de nome Antero, emancipado pelo Imperador Tibério, passeava às margens do rio Tibre, tropeçou em um peixe elétrico e curou-se de sua crise de gota. Fatos históricos relataram outras situações. William Gilbert, no século XVI 
considerado pai da eletroterapia moderna, Joham Jottob Krugger, em 1744, e Jean Louis Jalbert também utilizaram a eletricidade como recursos terapêuticos e novos adventos impulsionaram a eletroterapia como conhecimento científico. O reconhecimento da eletroterapia como recurso oriundo da eletricidade estática e a corrente galvânica que surgiu após a Revolução Francesa mostram a evolução deste procedimento terapêutico [2].

Na década de 60, após a publicação da Teoria da Comporta por Melzack \& Wall em 1965, os aparelhos de estimulação elétrica passaram a ser utilizados no controle da dor [2].

A Estimulação Nervosa Elétrica Transcutânea (TENS) é uma corrente de baixa intensidade onde o contato entre o eletrodo e a pele são mecanismos indispensáveis na técnica terapêutica. Esses dados foram ratificados por Kitchen \& Basin [3].

Os eletrodos são constituídos de borracha siliconizada com impregnação de carbono. Tais eletrodos são reutilizáveis, geralmente acoplados à superfície cutânea com o uso de um gel eletricamente condutivo. Existem outros tipos de eletrodos disponíveis, porém Nolan relatou que os eletrodos de borracha-silicone são mais eficazes e economicamente viáveis [4].

Jadassohn [5] observou uma reação eczematosa em paciente medicado com iodofórmio, utilizado como cicatrizante. Alguns dias após, já com a melhora do quadro clínico, o autor reaplicou iodofórmio no tegumento do paciente, obtendo intensa reação eczematosa. No V Congresso Alemão de Dermatologia, Jadassohn comunicou sua observação, relatou que os agentes externos, chamados de contactantes representam uma grande fonte de contaminação.

Andrade et al. [6] relataram que o meio hospitalar, incluindo o ar, a água e as superfícies inanimadas que cercam o paciente, guardam íntima relação com as infecções hospitalares, podendo proporcionar focos de contato e de transmissão. Apesar das principais causas de infecção hospitalar estarem relacionadas com a susceptibilidade do doente à infecção e com os métodos de diagnóstico e terapêuticos, não se pode deixar de considerar os aspectos de assepsia e de higiene do ambiente hospitalar.

Muitos recursos para se evitar a ocorrência do problema vêm sendo utilizados. O Center for Disease Control [7] referiu que as organizações de saúde têm desenvolvido normas de assepsia e higiene hospitalar. Schaefer [8] ratificou que essas normas são universais porque devem ser aplicadas a todos os doentes, em todos os tipos de tratamentos e para todos os instrumentos e equipamentos. Os protocolos propostos atribuem ênfase especial às barreiras de proteção contra os microrganismos.

Segundo Russo et al. [9], a crescente incidência de doenças transmissíveis conduz à necessidade de uma conscientização sobre os riscos reais de contaminação das mais diversificadas formas terapêuticas, dentre elas em especial a fisioterapia.
Sabe-se que, em termos de fisioterapia, pouco se conhece sobre os aspectos microbiológicos que envolvem esta atividade, fato que despertou receio e apreensão sobre o mecanismo de se identificar focos de contato e de transmissão de agentes patogênicos, dentre elas os causadores de dermatite de contato, com registros em outros países, evidenciando-se a necessidade de reconhecer a situação para estabelecermos uma abordagem mais específica com resultados mais concretos.

\section{Material e métodos}

Foram coletadas 24 amostras para pesquisa nos serviços de fisioterapia, situados na região da Baixada Fluminense, Rio de Janeiro, no período de maio a julho de 2002. A análise dos materiais foi realizada no laboratório de microbiologia e imunologia do programa de mestrado em ciências biológicas da Faculdade de Ciências Biológicas e da Saúde da Universidade Iguaçu. Os eletrodos condutores de eletroestimulação, de tamanho e marcas diversificadas utilizados em pacientes, foram submetidos à fricção longitudinal na superfície horizontal com o auxílio de um suabe embebido em solução salina (cloreto de sódio 0,9\%). No tempo máximo de duas horas após a coleta foram semeadas em meio de cultura de Brewer e Sabouraud. O meio de Brewer foi incubado em estufa a $37^{\circ} \mathrm{C}$ por 24 horas. O crescimento obtido foi repicado para meios de cultura Agar-sangue, Agar-hipertônico-manitol e meio seletivo para os gêneros Pseudomonas e Staphylococcus. As colônias desenvolvidas foram identificadas por caracteres culturais e provas bioquímicas de identificação, através do sistema BioMerieux Vitek. O crescimento fúngico no meio de Sabouraud foi identificado por caracteres morfológicos, culturais e provas bioquímicas quando necessárias.

\section{Resultados}

Das 24 amostras dos eletrodos de borracha siliconizada carbonizada de eletroestimulação analisadas, 59,5\% apresentaram a ocorrência de agentes bacterianos e/ou agentes fúngicos, nos serviços de fisioterapia por municípios pesquisados na região da Baixada Fluminense, Rio de Janeiro.

Encontrou-se uma freqüência mais elevada para os bioagentes fúngicos $(42,5 \%)$, enquanto que os bacterianos apresentaram 17,0 \% (Tabela I).

De acordo com a ocorrência de agentes bacterianos nos eletrodos de eletroestimulação, foi encontrada uma freqüência igualmente distribuída entre Pseudomonas aeruginosa e Staphylococcus aureus (Tabela II).

$\mathrm{Na}$ ocorrência de agentes fúngicos, houve uma freqüência bem distribuída de acordo com a seguinte ordem: Alternaria spp. 4,25\%, Aspergillus spp. 8,5\%, Cladosporium spp. 4,25\%, Candida albicans 8,5\%, Penicillium spp. 8,5\%, Nigrospora spp. 4,25\%, Sporothrix spp. 4,25\% (Tabela III). 
Tabela I - Distribuição de bioagentes bacterianos e fúngicos em 24 amostras coletadas nos eletrodos de eletroestimulação, utilizados nos serviços de fisioterapia por municípios pesquisados.

\begin{tabular}{lcccccc}
\hline Municípios & \multicolumn{2}{c}{$\begin{array}{c}\text { Agentes } \\
\text { bacterianos }\end{array}$} & \multicolumn{2}{l}{$\begin{array}{l}\text { Agentes } \\
\text { fúngicos }\end{array}$} & \multicolumn{2}{c}{ Totais } \\
\hline$N^{\circ}$ & $(\%)$ & \multicolumn{2}{c}{$\mathrm{N}^{\circ}$} & $(\%)$ & $N^{\circ}$ & $(\%)$ \\
\hline Belford Roxo & 00 & 00 & 02 & 8,5 & 02 & 8,5 \\
Mesquita & 02 & 8,5 & 04 & 17,0 & 06 & 25,5 \\
Nova lguaçu & 01 & 4,25 & 00 & 00 & 01 & 4,25 \\
Japerí & 01 & 4,25 & 02 & 8,5 & 03 & 12,75 \\
Queimados & 00 & 00 & 02 & 8,5 & 02 & 8,5 \\
São João de Meriti & 00 & 00 & 00 & 00 & 00 & 00 \\
Totais & 04 & 17,0 & 10 & 42,5 & 14 & 59,5 \\
\hline
\end{tabular}

Tabela II - Ocorrência de agentes bacterianos por gênero e espécies em 24 amostras coletadas nos eletrodos de eletroestimulação, utilizados nos serviços de fisioterapia.

\begin{tabular}{lll}
\hline Gênero e especies & No $^{\circ}$ & (\%) \\
\hline Pseudomonas aeruginosa & 02 & 8,5 \\
Staphylococcus aureus & 02 & 8,5 \\
Totais & 04 & 17,0 \\
\hline
\end{tabular}

Tabela III - Ocorrência de agentes fúngicos por gênero e espécies em 24 amostras coletadas nos eletrodos de Eletroestimulação, utilizados nos serviços de fisioterapia pesquisados.

\begin{tabular}{lcc}
\hline Gênero e especies & $\mathbf{N}^{\circ}$ Amostras + & (\%) \\
\hline Alternaria spp & 01 & 4,25 \\
Aspergillus spp & 02 & 8,5 \\
Candida albicans & 02 & 8,5 \\
Cladosporium spp & 01 & 4,25 \\
Nigrospora spp & 01 & 4,25 \\
Penicillium spp & 02 & 8,5 \\
Sporothrix schenckii & 01 & 4,25 \\
Totais & 10 & 42,5 \\
\hline
\end{tabular}

\section{Discussão}

Lima et al. [10] relataram que grande parte das infecções cutâneas é causada por fungos e bactérias, estando estas isoladas ou em conjunto. Enfatiza-se a possibilidade da ocorrência de infecção hospitalar, não somente pela existência de bioagentes patogênicos, mas pela suscetibilidade do indivíduo à infecção independente dos aspectos de limpeza do ambiente e respectivos equipamentos. Schaefer [8] relatou a importância das normas universais de assepsia, desinfecção e esterilização para todos os pacientes, instrumentos e equipamentos como forma de controle de infecção e biossegurança, chamando-nos a atenção para a realização de um estudo mais específico voltado à fisioterapia.
Santos [11] corroborou com Rey [12], quando disse que a alta umidade entre diversos segmentos corporais suporta a atividade e o crescimento de grande quantidade de bactérias, fungos e leveduras. Em nossos estudos, das 24 amostras dos eletrodos de borracha siliconizada carbonizada de eletroestimulação analisadas, houve uma freqüência de 59,5 \% de agentes bacterianos e/ou fúngicos, confirmando a necessidade de conscientização dos profissionais de fisioterapia sobre os riscos de contaminação por microrganismos. Silva [13] definiu que a infecção implica a colonização de células, tecidos ou cavidades corporais do hospedeiro, enquanto que a colonização indica a presença do microrganismo sem causar doença.

Diaz \& Rojas [14] alertaram para o fato de que todas as superfícies, principalmente as horizontais, devem ser limpas, pois a força de gravidade facilita a produção e proliferação de microrganismos veiculadores de contaminação e infecção. Rey [12] relatou que a pele apresenta uma microbiota, com predomínio de espécies do gênero Staphylococcus aureus, além de bacilos gram-negativos, representados principalmente por enterobactérias. A freqüência de positividade nos eletrodos de eletroestimulação em nosso estudo para agentes bacterianos apresentou-se menor que para agentes fúngicos (17,0 \% e 42,5\%, respectivamente).

Com relação aos agentes bacterianos, foi encontrada uma freqüência igualmente distribuída entre Pseudomonas aeruginosa (50\%) e Staphylococcus aureus. Adams et al. [15], Levy et al. [16], Santos et al. [17], Santos et al. [18] e Gould [19] ratificaram que o Staphylococcus aureus, enquanto um dos membros patogênicos da microbiota do homem, é encontrado em inúmeras partes do corpo, como fossas nasais, mãos, garganta, intestino, e principalmente pele e mucosas. O mesmo foi descrito por Zaits et al. [20] quanto aos elementos fúngicos, citando a candidose como ubíqua e a Candida albicans como integrante desta microbiota. E este microorganismo pode ser transmitido de pessoa para pessoa, através do contato direto ou indireto [21,22].

Morrinson et al. [23], Hosking et al. [24], Jantunem et al. [25], Verscharaegen et al. [26], Wald et al. [27] evidenciaram que as infecções por Aspergillus representam a segunda causa mais comum de infecção por fungos em pacientes. Cahill [328], ao realizar biópsias de pele com aspergilose cutânea por Aspergillus niger, confirmou sua patogenia colocando a pele contaminada como transmissor e a água como veiculadora do patógeno, o que ratifica a possibilidade de as placas eletrocondutoras serem mediadoras destes patógenos com a pele. Enquanto que Austwich \& Longbottom [29] se referiram a uma outra espécie, o Aspergillus fumigatus, como sendo de importância clínica nas infecções e alergias. Nossos estudos apontaram para uma freqüência bem distribuída de agentes fúngicos na seguinte ordem: Alternaria spp. 4,5\%, Aspergillus spp. 8,5 \%, Candida albicans 8,5\%, Penicillium spp. 8,5\%, Cladosporium spp. 4,25\%, Nigrospora spp. 4,25\% e Sporothrix spp. 4,25\%. Frampton [1] alertou sobre a irritação cutânea durante a aplicação prolongada, fazendo-se necessária a limpeza da área a serem aplicados os eletrodos a fim de evitar essas irritações. 
Frampton [1] ratificou que a resposta alérgica aos eletrodos, à fita adesiva, ou ao gel representam o principal problema à aplicação do TENS. A Organização Mundial de Saúde (OMS/ WHO) considera as parasitoses como elementos de máxima importância nas ciências da Saúde. Baseados nessas informações, Madeira-Oliveira et al. [30] relataram a relevância da inclusão da disciplina de parasitologia na formação acadêmica de fisioterapia, da qual pouco se conhece sobre os aspectos microbiológicos que envolvem a prática terapêutica. $\mathrm{O}$ resultado da pesquisa aponta para a necessidade de um protocolo de assepsia eficaz destes eletrodos, nos serviços de fisioterapia, promovendo o bem estar físico e a integridade dos pacientes.

\section{Conclusão}

Registra-se na região da Baixada Fluminense, Rio de Janeiro, nos serviços de fisioterapia, a ocorrência de bioagentes patogênicos nos eletrodos de borracha siliconizada com impregnação de carbono, utilizados na eletroanalgesia transcutânea.

Entre as amostras analisadas, 59,5 \% conferiram positividade de patógenos com predominância dos elementos fúngicos em 42,5\% e bacterianos em $17 \%$.

Levanta-se a suposição de que a freqüência de microrganismos patogênicos nos eletrodos associados a microbiota cutânea do homem, baixa do sistema imune e técnica inadequada de aplicação promovam a ocorrência de possíveis doenças dermatológicas.

Considerando-se a análise dos resultados, relata-se a necessidade da realização de técnica asséptica na região cutânea de aplicação da eletroanalgesia no homem e nos eletrodos.

Faz-se necessário um cuidado preventivo e de biossegurança no que se refere à prática fisioterapêutica em relação a bioagentes patogênicos. É preciso, também, que se dê continuidade na pesquisa com fundamentação na investigação dos bioagentes patogênicos na abordagem fisioterapêutica, identificando procedimentos apropriados para desinfecção dos eletrodos e da pele.

\section{Referências}

1. Frampton VM. Pain control with the aid of transcutaneous nerve stimulation. Physiotherapy 1982;68(3):77-81.

2. Leitão A, Leitão V. Clínica de reabilitação. 1a ed. São Paulo: Atheneu; 1995. p.313-4.

3. Kitchen S, Basin S. Eletroterapia de Clayton. 10a ed. São Paulo: Manole; 1998. p.350.

4. Nolan MF. Conducticve differences in electrodes used with transcutaneous electrical nerve stimulation devices. Phys Ther 1991;71:746-51.

5. Jadassohn J. [1985]. Tur Kenntnis Der Medikamentosen Dermatosen. Verhandeugen. Deutchen Dermatigishen Gereleschaet. Finster Congrees. Graz Wien: W Braunmiller; 1896. p.106.

6. Andrade D, Angerami ELS, Padovani CR. Condição microbiológica dos leitos hospitalares antes e depois de sua limpeza. Rev Saúde Pública 2000;34(2):163-9.

7. Center For Disease Control. Measles on a college Campus - Ohio. MMWR Morb Mortal Wkly Rep 1990;39(1):29.

8. Schaefer MB. The new CDC surgical water recommendations: why they should be implemented and what they require. Compend Contin Educ Dent 1996;17(6):612-20.
9. Russo EMA, Carvalho RC, Lorenzo JL, Garone Netto N, Cardoso MV, Grossi E. Avaliação da intensidade de contaminação de pontas de seringa tríplice. Pesqui Odontol Bras 2000;14(3).

10. Lima EO, Chaves LM., Oliveira, NMC. Isolamento de dermatófitos geofílicos da região litorânea de João Pessoa - Paraíba - Brasil. An Bras Dermatol 1999;74(2):127-32.

11. Santos BMO. Estudo longitudinal sobre portador são de Staphylococcus aureus em alunos de um curso de auxiliar de enfermagem. Rev Soc Bras Med Trop 1999;4(32):41-4.

12. Rey L. Dicionário de termos técnicos de medicina e saúde. São Paulo: Guanabara Koogan 1999; p.825.

13. Silva CHPM. Bacteriologia: texto ilustrado. Rio de Janeiro: Eventos; 1999. p.53.

14. Diaz CAA, Rojas FJC. Processo de limpieza en el hospital. Todo Hosp 1996;126:49-53.

15. Adams BC, Marrie TTJ. Hand carriage of aerobic gram-negative rods may not be transient. J Hyg 1982;89:33-46.

16. Levy CE, Costa JC, Lama J, Furlan MLS, Toloy RC, Pasti MJ, Takeda E. Papel epidemiológico das mãos nas infecções hospitalares. Rev Soc Bras Med Trop 1988;21:89.

17. Santos BMO, Aguillar OM, Takakura MS. Colonização simultânea de Staphylococcus aureus na cavidade nasal e mãos de portadores sãos de um hospital escola. Rev Microbiol 1990;21:309-14.

18. Santos BMO, Scochi CGS, Garcia E, Souza MT. Prevalência de portadores sãos de Staphylococcus aureus em pessoal de enfermagem de unidades pediátricas de um hospital geral escola. Parte I. Rev Paul Hosp 1990;83:24-9.

19. Gould D. Nurses' hands as vectors of hospital-acquired infection: a review. J Adv Nurs 1991;16:1216-25.

20. Zaitz C, Campbell I, Marques SA, Ruiz LRB, Souza VM. Compêndio de micologia médica. São Paulo: MEDSI; 1998. p. 82.

21. Davis BD, Dulbecco R, Eisen HN, Ginsberg HS, Wood WB. Relações hospedeiro-parasita nas doenças bacterianas. In: Davis BD, Dulbecco R, Eisen HN, Ginsberg HS, Wood WB (eds). Microbiology. São Paulo: Edart; 1973. p. 9-54.

22. Rouquayrol MZ, Veras FMF. Doenças transmissíveis e modos de transmissão. In: Rouquayrol MZ (ed). Epidemiologia e saúde. 4a ed. Rio de Janeiro: MEDSI; 1994. p. 217-68.

23. Morrinson VA, Haake RJ, Weisdorf DJ. Non-Candida fungal infections after bone marrow transplantation: risk factors and outcome. Am J Med 1994;96:497-503.

24. Hosking M, Macdonald N, Cornel G. Liposomal amphotericin $\mathrm{B}$ for postoperative Aspergillus fumigatus endocarditis. Ann Thorac Surg 1995;19:859-60.

25. Jantunen E, Ruutu P, Niskanen L, Volin L, Parkkali T, KoukilaKahkola P, Ruutu T. Incidence and risk factors for invasive fungal infections in allogeneic BMT recipients. Bone Marrow Transplant 1997;19(8):801-8.

26. Verschraegen CF, Van Besien KW, Dignani C, Hester JP, Anderson BS, Anaissie E. Invasive Aspergillus sinusitis during bone marrow transplantation. Scand J Infect Dis 1997;29:436-8.

27. Wald A, Leisenring W, Van Burik J, Bowden RA. Epidemiology of Aspergillus infections in a large cohort of patients undergoing bone marrow transplantation. J Infect Dis 1997;175:1459-66.

28. Cahill KM, Mofty AM, Kawaguchi TP. Primary cutaneous Aspergillosis. Arch Dermatol 1967;96:545-7.

29. Austwick PKC, Longbottom JL. Medically important Aspergillus species. In: Lennette EH, Balows A, Hausler Jr WJ, Truant JP. Manual of clinical microbiology. 3a ed. Washington: American Society for Microbiology; 1980; p.55-8.

30. Madeira-Oliveira JT, Machado RO, Werneck JGE, Mata LJF. Sugestão para inclusão da disciplina ou conhecimento de parasitologia no currículo pleno da graduação em fisioterapia. 52a Reunião da SBPC. Universidade de Brasília, DF; 2000. 